\title{
Desafíos de la víctima frente a la figura del acusador privado dentro del proceso penal colombiano.
}

\section{Challenges of the victim against the figure of the private accusator within the colombian criminal procedure.}

\author{
Autor: Katrim Johana De La Hoz Del Villar ${ }^{1}$ \\ Correspondencia: katrimdelahoz@hotmail.com
}

\begin{abstract}
RESUMEN
La figura del acusador privado fue introducida al ordenamiento jurídico colombiano por medio de la Ley 1826 de 2017 con el fin de proponer estrategias que propugnen por la descongestión del orden judicial, en especial el sistema penal acusatorio. Esta figura consiste en una acción privada por medio de la cual la víctima, su representante o cualquier autoridad distinta a la Fiscalía General de la Nación en cuyas funciones recaigan facultades investigativas, podría efectuar el ejercicio de la acción penal en los casos determinados que expresamente consagre el legislador. Esta ponencia esbozará entonces los diferentes desafíos a los cuales se enfrentará la víctima a lo largo del proceso penal en ejercicio de la acción penal privada.
\end{abstract}

\section{Palabras claves:}

Acusador privado, acción penal, víctimas, sistema acusatorio penal colombiano, desafíos.

\footnotetext{
${ }^{1}$ Estudiante del programa de Derecho de la Universidad del Atlántico y estudiante de Administración Pública de la Escuela Superior de Administración Pública ESAP. Bachiller con énfasis en Educación en 2013 en la Institución Educativa Escuela Normal Superior Nuestra Señora de Fátima, Colombia. Ha trabajado en proyectos del área de Derecho, como representante estudiantil del semillero de investigación denominado "Derecho, Violencia y Conflicto", adscrito al grupo de investigación Pedro Lafont Pianetta.
} 


\begin{abstract}
The figure of the private accuser was introduced to the Colombian legal system by means of law 1826 of 2017 in order to propose strategies that advocateed by the decongestion of the judicial order, in particular the penal criminal systems. This figure consists of a private action by means of which the victim, his representative or any other authority other than Fiscalia General de la Nación in whose functions the investigative powers fall, could carry out the exercise of the criminal action in the Specific cases that the legislator expressly enshrines. This paper will then outline the various challenges facing the victim throughout the criminal proceedings in the exercise of private criminal action.
\end{abstract}

\title{
Key words:
}

Private accuser, criminal action, victims, Colombian criminal indictment system, challenges.

\section{Introducción}

Desde los tiempos más remotos la persona que sufría un daño ejercitaba la acción penal. Eran los tiempos de la venganza privada, esa época fatídica de la humanidad en la cual la ley del Talión fue la máxima expresión del derecho penal, el tiempo en que existía la acción popular en el derecho romano y la privada en el germano. En la actualidad, por el contrario, el derecho penal en general, se ha tornado más garantista y menos represivo, más respetuoso de los derechos humanos, más integral. Esta época de luz en la cual el acusado se presume inocente, donde la libertad es la generalidad y la privación de la misma la excepción, la época de la humanidad en que la buena fe es un principio constitucional.

Dentro de una sociedad diferente e incluso con un derecho penal garantista también se han presentado dificultades, no tan grandes como la monarquía que oprimía al demos de la gran obra de Lope de Vega "Fuente Ovejuna", pero si lesivas de los derechos fundamentales de las personas. La congestión judicial se 
convierte entonces en la situación que retrasa el cumplimiento del deber del Estado de impartir justicia y la causa primordial que no permite a los ciudadanos hacer efectivos sus derechos.

Con el fin de proponer estrategias que propugnen por la descongestión del orden judicial, en especial el sistema penal acusatorio, el Congreso de la República expidió la ley 1826 del 12 de enero de 2017 "Por medio de la cual se establece un procedimiento penal abreviado y se regula la figura del acusador privado". Esta ley introduce a la legislación un procedimiento penal especial abreviado que, respetando todas las garantías constitucionales que representan el derecho al debido proceso hace mucho más corto y celero el procedimiento penal para algunas conductas delictivas previamente establecidas en el ámbito de aplicación de esta ley (Fiscalía General de la Nación, 2017).

Por otro lado, esta ley introduce, además, con el propósito de propugnar por la descongestión judicial la figura del acusador privado. Figura que se estudiará en la presente ponencia, desarrollando primeramente la historia de la llamada acción penal privada, esbozando su ámbito de aplicación dentro del sistema acusatorio penal colombiano, analizando además la monopolización de la acción penal y su desmonopolización a través de la conversión de la acción pública a privada, y por último estableciendo los desafíos que reposan sobre la víctima dentro de la implementación de esta figura.

\section{Metodología.}

El presente trabajo investigativo se desarrollará bajo los albores del enfoque cualitativo, toda vez que la información será analizada, sistematizada e 
interpretada a manera de conceptos, relaciones, explicaciones. Se trata además de una investigación mixta, de tipo explicativa y descriptiva, en el entendido que se pretende determinar los desafíos de la víctima frente a la figura del acusador privado dentro del proceso penal, a través del estudio y análisis de la misma. Las técnicas de recolección de la información serán secundarias puesto que el proceso investigativo se llevará a cabo a través de revisiones bibliográficas.

\section{Resultados y discusiones.}

\section{Antecedentes de la acción privada}

La acción penal se ha desarrollado históricamente en conjunto con los sistemas procesales penales, de ahí a que su función y ejercicio varíe de acuerdo a la ideología política y jurídica imperante en las distintas etapas históricas. En los orígenes del proceso penal la reacción ante el injusto implicaba necesariamente la existencia de un conflicto entre victimario y víctima, sin la existencia de un tercero que dirimiera el conflicto, de tal forma que la venganza privada constituía el medio por el cual se castigaba el daño causado al ofendido (Zamora, 2002). Es la figura de la acción privada que de acuerdo con Roxin (2000) se desarrolló en el Derecho germánico, con la exigencia según la cual esta solamente podía ser promovida por el ofendido o su familia.

En los procedimientos penales de Grecia y Roma republicana, en donde primó el sistema acusatorio puro, la acusación era de carácter popular. De acuerdo con esta figura cualquier persona podía formular una acusación, es decir, no solo la víctima del delito podía ejercer la acción penal, sino que el pueblo también podía solicitar la represión del delito, en miras del interés ciudadano y el sentimiento de corresponsabilidad del mantenimiento del derecho penal. (Chávez, 2013) 
Durante la edad media, el derecho canónico implantó un sistema propio con características muy distintas al anterior, denominado inquisitivo. En este nuevo sistema se consolida el concepto de acción penal pública, la cual atribuía a un funcionario público la facultad para ejercer la acción penal de manera oficiosa, excluyendo a los particulares de su ejercicio y donde además las tres funciones básicas del proceso: la acusación, la defensa y el juzgamiento, eran ejercidos por una misma institución. Esta concepción estuvo ligado al interés de lograr el control social y el sometimiento de los súbditos al Estado por medio del empleo desmedido del Derecho Penal y de la pena (Maier, 2003).

Posteriormente, a mediados del siglo XVIII, la influencia de las ideas políticas nacientes en la ilustración permitió la secularización y racionalización del derecho penal, dando lugar al nacimiento del denominado "Derecho penal liberal", inspirado en principios garantistas y limitadores del ius puniendi, lo que influiría enormemente en la trasformación del proceso penal. Como consecuencia a estos cambios significativos, surgió entonces un sistema de procedimiento mixto que acogía características propias del sistema inquisitivo, así como también del sistema acusatorio. En este sistema al igual que en el inquisitivo, el ejercicio de la acción penal es de carácter público, en este caso, es deber del Estado la persecución del delito; además dentro de este existe división de las funciones de acusar y juzgar, características propias del sistema acusatorio. En palabras de Claus Roxin "Con el fortalecimiento del concepto de Estado, se mantuvo el interés en que la acción penal estuviera a cargo del propio Estado, pero a través de un ente de investigación autónomo y especializado, aspecto que la doctrina ha llegado a denominar principio de oficialidad" (Roxin, 2000).

\section{2. Ámbito de aplicación}


La ley 1826 del 12 de enero de 2017 introduce la figura del acusador privado dentro del proceso penal, esta figura

consiste en una acción privada por medio de la cual la víctima, su representante o cualquier autoridad distinta a la Fiscalía General de la Nación en cuyas funciones recaigan facultades investigativas, podría efectuar el ejercicio de la acción penal en los casos determinados que expresamente consagre el legislador. (Sánchez, 2013, $p, 2)$

El Acto legislativo 006 de 2011 por medio del cual se reformó el numeral 4 del artículo 235, el artículo 250 y el numeral 1 del artículo 251 de la constitución política introdujo la figura del acusador privado al ordenamiento jurídico colombiano. Está figura la contempla el artículo 250 constitucional así

Atendiendo la naturaleza del bien jurídico y la menor lesividad de la conducta punible, el legislador podrá asignarles el ejercicio de la acción penal a la víctima a otras autoridades distintas a la Fiscalía General de la Nación. En todo caso, la Fiscalía General de la Nación podrá actuar de forma preferente. (Constitución Política de Colombia de 1991. Título VII, capítulo 6, artículo 250, parágrafo $2^{\circ}$ )

Ahora bien, teniendo como fundamento lo anterior el Congreso de la República regula por medio de la ley 1826 de 2017 esta figura y señala expresamente los casos en que la víctima podría ejercer la acción penal, siempre y cuando sea por intermedio de su abogado. Además, dispone que el procedimiento a seguir por la misma cuando decida acudir a dicha figura será el procedimiento penal abreviado. 
Por otro lado, los estudiantes de consultorio jurídico de las universidades debidamente acreditadas ante el Ministerio Nacional de Educación pueden actuar en representación del acusador privado en los términos de ley. Es menester aclarar, además, que bajo ninguna circunstancia puede figurar más de un (1) acusador privado dentro de un proceso penal.

El acusador privado puede conocer de las conductas punibles previstas para el trámite de procedimiento abreviado. El catálogo de conductas punibles sobre las cuales se les aplica dicho procedimiento se encuentra consagrado en el artículo 534 del Código de Procedimiento Penal, Ley 906 de 2004, introducido por la Ley 1826 de 2017, el cual se divide en dos partes: primeramente, se estipulan las conductas querellables conforme a lo consagrado en el artículo 74 de la Ley 906 de 2004. Por otro lado, las conductas investigables de oficio que se rigen por el procedimiento penal abreviado. Es decir, los tipos penales expresamente consagrados en el artículo 10 de la Ley 1826 de 2017, conductas punibles que sin ser querellables se rigen por el procedimiento abreviado introducido al ordenamiento jurídico por la misma Ley.

Sin embargo, es menester aclarar que la figura del acusador privado no será aplicable en aquellas conductas que atenten contra bienes del Estado. Así como en otras circunstancias tales como: cuando no se acredite sumariamente la condición de la víctima de la conducta punible, cuando además no esté plenamente identificado o individualizado el sujeto investigado, cuando el indiciado pertenezca a una organización criminal y el hecho esté directamente relacionado con su pertenencia a esta, cuando el indiciado sea inimputable, cuando los hechos guarden conexidad o estén en concurso con delitos frente a los que no procede la conversión de la acción penal, cuando se presente esta causal es importante tener en cuenta que, el procedimiento aplicable será el ordinario puesto que así lo 
consagra el artículo 10 de la Ley 1826 de 2017, siendo preferente el procedimiento aplicable a las conductas que no se tramitan bajo el procedimiento penal abreviado.

Así también, está figura no será aplicable cuando la conversión de la acción penal implique riesgo para la seguridad de la víctima, cuando no haya acuerdo entre todas las víctimas de la conducta punible, cuando existan razones de política criminal, investigaciones en contexto o interés del Estado que indiquen la existencia de un interés colectivo sobre la investigación, y finalmente, cuando la conducta sea objetivamente atípica, caso en el cual el fiscal procede al archivo de la investigación.

Por último, se hace necesario esbozar que conforme a lo consagrado en la Ley 1826 de 2017, en lo relacionado a las causales que impiden la aplicación de la figura del acusador privado, ésta tampoco procede cuando se trate de procesos adelantados por el sistema de responsabilidad para adolescentes, sin perjuicio de que los mismos sean regulados por el procedimiento abreviado (Fiscalía General de la Nación, 2017).

\section{Monopolización de la acción penal y su desmonopolización a través de la conversión de la acción pública a privada}

El derecho penal público durante la época de la monarquía y la república era instruido de oficio por un magistrado y esta forma de procedimiento se denominó la cognicio; sin embargo, con el advenimiento del imperio, se planteó la posibilidad de hacer un trasplante del modelo procesal penal privado al procedimiento penal público. De esta forma, los particulares podrían ejercer las funciones del 
magistrado instructor en el derecho penal público y esta figura se le denominó la accusatio. (Beltrán y Vera, 2016)

Desde la antigüedad, hasta nuestros días el Estado por medio de sus magistrados, fiscales y demás miembros de la rama judicial, ha ostentado la facultad de ejercer la acción penal dentro del procedimiento reglado por el legislador. La acción penal es entonces "el mecanismo procesal real mediante el cual las víctimas de una conducta sancionada por el ordenamiento penal acceden a sus derechos de verdad, justicia y reparación" (Matusan, 2012). El ejercicio de esta acción en palabras de Couture (citado por Matusan,2012) comprende "el poder jurídico que tiene todo sujeto de derecho de acudir a los órganos jurisdiccionales para reclamarles la respuesta de una pretensión". Vincenzo Manzini (1975) en su obra "Tratado de Derecho Procesal Penal" constata lo anterior afirmando que todo delito da siempre lugar a la pretensión punitiva que se hace valer por la llamada acción penal.

Respecto lo anterior, en palabras de Carnelutti citado por Matusan (2012) la acción se puede concebir, de conformidad con la teoría que consideramos hoy históricamente preferible, como un derecho subjetivo autónomo (esto es, tal que pueda existir por sí mismo, independientemente de la existencia de un derecho subjetivo sustancial) y concreto (esto es, dirigido a obtener una determinada providencia jurisdiccional favorable a la petición del reclamante). $(p, 5)$

Luego de esbozarse un amplio bagaje conceptual respecto a la acción penal es menester mencionar que, el ejercicio de dicha acción ha llevado a que dentro del ordenamiento jurídico y social se genere una monopolización del derecho a 
ejercerla, fenómeno que recae principalmente en el Estado y más específicamente en su rama judicial.

En consonancia con lo anterior, a través de la Ley 1826 del 12 de enero de 2017, el congreso de la República introdujo al ordenamiento jurídico la figura del acusador privado como una medida para descongestionar el sistema procesal penal. Además, con esta figura se elimina el monopolio de la acusación que recaía en la Fiscalía General de la Nación y la desmonopoliza trasladando esta facultad a la víctima que podrá ejercer este derecho a través de apoderado judicial.

La desmonopolización de la acusación se entiende como un modelo del derecho procesal penal, que permite eliminar la concepción paternalista adquirida desde la revolución francesa, en donde el Estado, actuando a través de ministerios Fiscales y operando como garante de los bienes y la integridad de sus ciudadanos, era el único facultado para ejercer las funciones de investigar y acusar, desligando desde luego del proceso de juzgamiento a la víctima. (Benedetti y Torrado, 2013, p.5)

La conversión de la acción penal en privada favorece entonces a la desmonopolización de la acción e implica que "el acusador privado cuente con facultades y cargas procesales semejantes a las que tiene un fiscal dentro del proceso penal, con la salvaguarda de que éste no puede realizar actos complejos de investigación que comporten una grave afectación los derechos fundamentales". (Beltrán y Vera, 2016)

El manual expedido por la Fiscalía General de la Nación respecto de la ley 1826 de 2017 consagra todo lo referente al procedimiento que debe seguirse para 
la conversión de la acción pública a privada. Primeramente, se debe realizar la solicitud de conversión de la acción, para ejercerla la persona interesada en solicitar la conversión de la acción pública en privada deberá cumplir con las mismas calidades y requerimientos exigidos para el querellante legítimo, en consonancia con lo estipulado en el artículo 71 de la ley 906 de 2004.

Consecuentemente, puede solicitar la víctima la conversión de la acción de forma escrita y acreditar sumariamente su calidad ante el fiscal del caso, siempre y cuando no se haya realizado el traslado del escrito de acusación.

Como primera medida, se debe verificar si se trata de un delito querellable o investigable de oficio. En el primer escenario, el fiscal del caso decide sobre la conversión de la acción pública en privada, una vez se haya realizado la audiencia de conciliación sin acuerdo entre las partes, y hasta antes del traslado del escrito de acusación. En el segundo caso, es decir, cuando la investigación penal se adelante de manera oficiosa, la solicitud de conversión en acción privada procede, siempre y cuando no se haya dado traslado del escrito de acusación por parte del fiscal del caso. De ser así, la competencia para adelantar el proceso penal debe ser exclusivamente de la Fiscalía General de la Nación. En el segundo caso, es decir, cuando la investigación penal se adelante de manera oficiosa, la solicitud de conversión en acción privada procederá siempre y cuando no se haya dado traslado del escrito de acusación por parte del fiscal del caso, pues de ser así, la competencia para adelantar el proceso penal será exclusivamente de la Fiscalía General de la Nación. (Fiscalía General de la Nación, 2017, p.34)

Respecto a los casos en que se presente concurso de conductas punibles estás se tramitaran por el procedimiento ordinario siendo preferente el proceso de 
los delitos no comprendidos dentro del procedimiento penal abreviado. En este caso no podrá entonces convertirse la acción penal.

Otro aspecto a tener en cuenta, dentro de este procedimiento de conversión es cuando exista una pluralidad de víctimas, en este caso, debe mediar acuerdo entre todas y cada una de ellas y dicha solicitud debe comprender la manifestación expresa de cada víctima, puesto que si no se da dicho acuerdo no se podrá realizar la conversión de la acción penal. En caso de desacuerdo se mantendrá entonces la titularidad de la acción penal en cabeza de la Fiscalía General de la Nación. Es menester mencionar que, en los casos en que aparezca una nueva víctima cuando ya se haya iniciado el trámite, esta podrá adherirse al trámite de la acción privada.

Por último, es importarte adherir que, el fiscal tendrá (1) mes contado a partir del día del recibo de la solicitud de conversión de la acción para resolver de fondo sobre ellos. Si la autoriza, debe señalar al peticionario la identidad e individualización del indiciado(s), los hechos que son objeto de la acción privada y su calificación jurídica provisional. En todo caso, el escrito de acusación presentado por el acusador privado debe estar acompañado de la autorización u orden emanada del fiscal. En caso de demostrarse que el fiscal y/o el acusador privado tienen conocimiento de alguna de las causales que impiden la conversión y no lo hayan manifestado, proceden las respectivas investigaciones disciplinarias y penales, sin perjuicio de la reversión.

\section{Desafíos de la víctima frente a la implementación de la figura del acusador privado}


Las Organización de las Naciones Unidas (citado por Marchiori, 2006) expresa que se entenderá por víctimas las personas que individual o colectivamente hayan sufrido daños, inclusive lesiones físicas o mentales, sufrimiento emocional, pérdida financiera o menoscabo sustancial de sus derechos fundamentales como consecuencia de acciones u omisiones que violen la legislación penal vigente en los Estados miembros, incluida la que prescribe el abuso del poder (p.174).

A su vez Marchiori (2006), define la víctima como "la persona que padece un sufrimiento físico, emocional y social a consecuencia de la violencia, de una conducta agresiva antisocial, a través del comportamiento del individuo delincuente que transgrede las leyes de su sociedad y cultura". Las víctimas, por lo general, acceden a sus derechos de verdad justicia y reparación a través del mecanismo procesal denominado acción penal.

Respecto a este mecanismo procesal, denominado acción penal, la víctima obtiene una reparación integral del mal que se la sido causado. En pro de que esta acción cumpla con su finalidad el Congreso de la República de Colombia expidió el 12 de enero de 2017, la Ley 1826 por medio del cual se regula el procedimiento penal abreviado y la figura del acusador privado, modificando el artículo 66 de la Ley 906 de 2004, quedando así

El Estado, por intermedio de la Fiscalía General de la Nación, está obligado a ejercer la acción penal y a realizar la investigación de los hechos que revistan las características de una conducta punible, de oficio o que lleguen a su conocimiento por medio de denuncia, petición especial, querella o cualquier otro medio, salvo las excepciones contempladas en la Constitución Política y en este código. 
No podrá, en consecuencia, suspender, interrumpir ni renunciar a la persecución penal, salvo en los casos que establezca la ley para aplicar el principio de oportunidad regulado dentro del marco de la política criminal del Estado, el cual estará sometido al control de legalidad por parte del juez de control de garantías.

Cuando se autorice la conversión de la acción penal pública a privada, y entre tanto esta perdure, la investigación y la acusación corresponderán al acusador privado en los términos de este código.

De acuerdo a lo anterior, es claro que dentro del proceso penal la víctima podrá ejercer la acusación a partir de la entrada en vigor de esta ley, por lo tanto, después de realizar el análisis expuesto a lo largo de esta ponencia, se hace necesario esbozar los diferentes desafíos a los cuales se enfrentara la víctima a lo largo del proceso penal.

El primero de los muchos desafíos a los que se verá enfrentada la víctima será cumplir con todos los requisitos formales para la presentación de la solicitud de conversión, previstos en los artículos 31, 32 y 33 de la ley 1826 de 2017, que adicionan tres nuevos artículos al Código de Procedimiento Penal. Está solicitud deberá ser dirigida al fiscal y deberá hacerse de forma escrita, acreditando sumariamente la condición de víctima de la conducta punible. El fiscal tendrá (1) mes desde la fecha de su recibo para resolver de fondo sobre la conversión de la acción penal.

Respecto al primer desafío, es indispensable mencionar que, a falta de algunos de los requisitos formales establecidos en el artículo 32 de la ley 1826 de 2017 el Fiscal General de la Nación o el fiscal delegado, podrán revertir la acción penal a través de decisión motivada con base en las causales expuesta en el 
artículo anteriormente mencionado. Por otro lado, si el acusador privado o su representante tuvieron conocimiento de alguna de las causales estipuladas en el artículo 32 de la Ley 1826 de 2017 y omitieron ponerla de manifiesto, se compulsarán copias para las correspondientes investigaciones disciplinarias y penales.

Otros de los desafíos que comporta la nueva ley, se enmarca en que, si bien es cierto que la víctima de un comportamiento punible puede solicitarle al fiscal, que en este caso es el legítimo titular de la acción penal, la conversión de la acción para asumir las funciones de investigación y acusación de los posibles autores o participes, no puede obviarse que ejercer dichas funciones puede resultar excesivamente oneroso para la víctima.

En este caso la conversión de la acción penal le entrega completamente la dirección de la investigación y el ejercicio de la acusación a la víctima por intermedio de su abogado o el estudiante de consultorio jurídico que lo represente, es decir la víctima tendrá las mismas funciones que le competen al Fiscal dentro de un proceso penal ordinario salvo los actos complejos de investigación, que deberán ser ordenados por el juez de control de garantías y coordinados por el fiscal competente. Respecto lo anterior, el punto central de este desafío recae en que la víctima tendrá que realizar los actos de investigación y la búsqueda de los elementos materiales probatorios por su propia cuenta puesto que se releva totalmente a la fiscalía y a la policía de sus funciones de investigar, acusar y probar en juicio la acusación. Dicha función supone entonces que, esta tiene el deber de realizar todas las actividades para lograr la identificación del responsable de la conducta punible y demostrar la configuración de los elementos de identificación del tipo penal, lo que conlleva a un enorme desafío puesto es evidente que un representante de víctimas no cuenta con la capacidad económica 
y técnica para poder agrupar todos los elementos materiales probatorios necesarios, que serán posteriormente llevados a juicio y conducirán al juez a lo largo del proceso para que este puede determinar la responsabilidad penal del procesado. (Benedetti y Torrado, 2013)

Adicionalmente, otro de los desafíos que reposan sobre la figura de la víctima se enmarca en que, aunque el acusador privado esté facultado para desarrollar actos de investigación directamente, cuando se trate de actos complejos en los que se puedan ver afectados derechos fundamentales, de manera excepcional debe solicitar su realización ante el Juez de Control de Garantías, cuya ejecución recaerá en la Fiscalía General de la Nación. Resulta entonces, que la víctima deberá acudir ante el Juez de Control De Garantías cada vez que pretenda realizar un acto complejo de investigación, estipulados estos en el artículo 34 de la Ley 1826 de 2007, este tramité no presenta un alivio a la posición del acusador privado, sino pues representa más trabajo para la víctima a lo largo del proceso.

Por último, en cuanto a la medida de aseguramiento, la víctima podrá autónomamente solicitar dichas medidas, lo que resulta un desafío para la misma puesto que esta debe contar con la imparcialidad, tecnicismo y objetividad suficiente para realizar una correcta adecuación típica y posteriormente solicitar dicha medida.

\section{Conclusiones}

La ley 1826 de 2017 introduce entonces la figura del acusador privado al ordenamiento jurídico colombiano. Esta figura le permite a la víctima ejercer la 
acción penal y releva casi que completamente al fiscal de su función constitucional de investigar y acusar a los autores y partícipes de comportamientos punibles.

Al analizar está figura queda claro que aplicándola se desmonopoliza la titularidad del derecho de la acción penal a través de la conversión de la misma. El proceso de conversión de la acción de publica a privada favorece entonces a la desmonopolización de la acción, como ya se ha mencionado a lo largo de esta ponencia, e implica que "el acusador privado cuente con facultades y cargas procesales semejantes a las que tiene un fiscal dentro del proceso penal, con la salvaguarda de que éste no puede realizar actos complejos de investigación que comporten una grave afectación los derechos fundamentales". (Beltrán y Vera, 2016)

Otra de las conclusiones preliminares que resultaron del presente trabajo investigativo, consiste en que la víctima que decida solicitar la conversión de la acción penal quedará enfrentada a múltiples desafíos. El debate queda abierto entonces, en cuanto a diversas dudas y lagunas que nos deja esta ley modificatoria del Código de Procedimiento Penal, tales como, si estarán o no los estudiantes de consultorio jurídico de las distintas universidades en capacidad de fungir como representante de la víctima dentro de los procesos donde se solicite la conversión de la acción penal.

Así pues, también es menester mencionar las dudas que quedan respecto a la responsabilidad que reposa sobre la víctima cuando decida fungir como acusador, puesto que está tendrá que realizar los actos de investigación y la búsqueda de los elementos materiales probatorios por su propia cuenta. Dicha función, resulta excesivamente onerosa y compleja debido a que un representante de víctimas no 
cuenta con la capacidad económica y técnica para poder agrupar todos los elementos materiales probatorios necesarios.

Por último, es menester aclarar que con la siguiente ponencia no se pretende generar simplemente críticas a la implementación de esta figura dentro del ordenamiento jurídico, sino que propugna por el estudio de esta figura teniendo en cuenta la realidad social del país.

\section{Referencias.}

Beltrán, D., \& Vera, O. (2016). El Acusador Privado En Colombia: ¿Hacia La Estratificación Del Derecho Penal? Revista Derecho, Debates \& personas. Obtenido de http://www.revistaderecho.co/index.php/es/edicion-3/item/52-elacusador-privado-en-colombia-hacia-la-estratificacion-del-derecho-penal

Benedetti, R., \& Torrado, L. (2013). Desmonopolización de la acusación penal en Colombia: Implementación de la figura del acusador particular en el procedimiento penal colombiano. Bogotá: Pontificia Universidad Javeriana.

Chaves Peña, E. (2013). La acción penal privada y su implementación en Colombia. Revista VIA IURIS. Enero - Junio, pp. 167-185

Correa, M., Jaimes, J., Cardozo, S. \& Mantilla, C. (2013). Estrategia para la disminución de violencias en la escuela en la ciudad de Bucaramanga. Revista Justicia, 18(24), 14-24. Recuperado de http://publicaciones.unisimonbolivar.edu.co/rdigital/ojs/index.php/justicia/arti cle/viewFile/136/138 
Fiscalía General de la Nación. (2017). Manual nuevo procedimiento penal abreviado y acusador privado. Bogotá: Serie legislativa - 1, Fiscalía General de la Nación.

Maier, J. (2003). Derecho Procesal Penal. Parte General: Sujetos procesales. Tomo II. Buenos Aires: Editores del Puerto.

Manzini, V. (1951). Tratado de Derecho Procesal Penal. Buenos Aires: Jurídicas Europa - América.

Marchiori, H. (2006). Los procesos de victimización. Avances en la asistencia a víctimas. In Ponencia presentada en el: Congreso Internacional de Derecho Penal y VII Jornada sobre Justicia Penal, Junio (Vol. 19).

Matusan, C. (2013). La acción penal privada y la afectación de derechos fundamentales. Revista VIA IURIS, 187 - 197.

Roxin, C. (2000). Derecho Procesal Penal. Buenos Aires: Editores del Puerto.

Sánchez, S. (2013). El acusador privado en Colombia, una aproximación desde los principios del Derecho Penal. Bogotá: Universidad Militar Nueva Granada. 

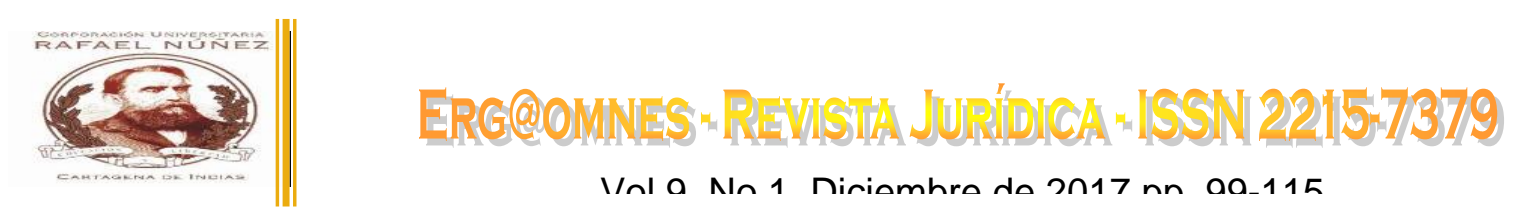

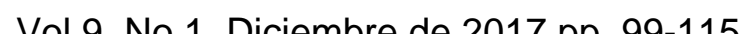

Trejos, L. (2013). Aproximación a las dinámicas del crimen organizado en la ciudad de Barranquilla. El caso del Frente José Pablo Díaz de las Autodefensas Unidas de Colombia (200-2006). Justicia, 118-134.

Vega, H. (2015). Aspectos dogmáticos y políticos criminales de la estructura general del delito en el sistema penal colombiano. Justicia, 27, 42-72. Recuperado de http://dx.doi.org/10.17081/just.3.27.320

Yáñez, M. (2013). El desplazamiento forzado en la jurisprudencia de la Corte Constitucional colombiana (1991-2003): momento previo a la declaratoria forma del estado de cosas inconstitucional. Revista Justicia, (23), 191-218. Barranquilla: Universidad Simón Bolívar

Zamora Grant, J. (2002). La víctima en el sistema penal. México. Instituto Nacional de Ciencias Penales. 